$\tau^{\text {He POpular SONG of THe Day }}$ Marcy gory

NANCY GRAY

OR

BALDWINS

BALLOON

Composed by GEOROE BURTON,LEM.

ShefField
The Universal MusiePublishing Co. PRICE 4/

LONDON B B. FELDMAN 84 OXFORD ST. 


\section{NANCY GRAY.}

Words by

OSIVALD LING.
Music by

GEORGE BURTON.

Moderato.

VUICE.

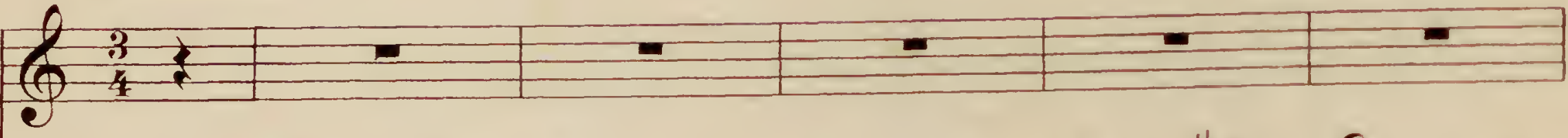

PIANO.



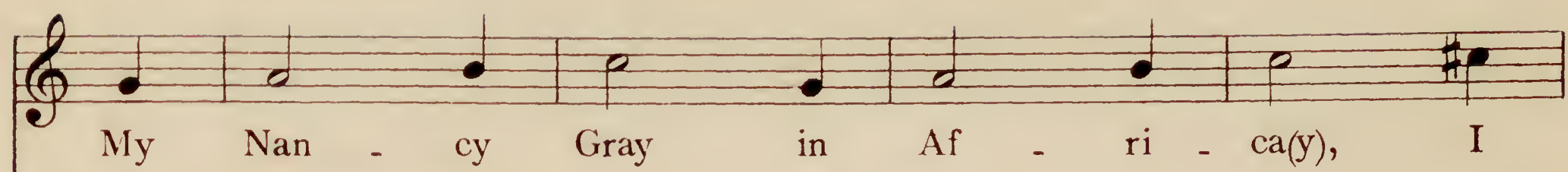

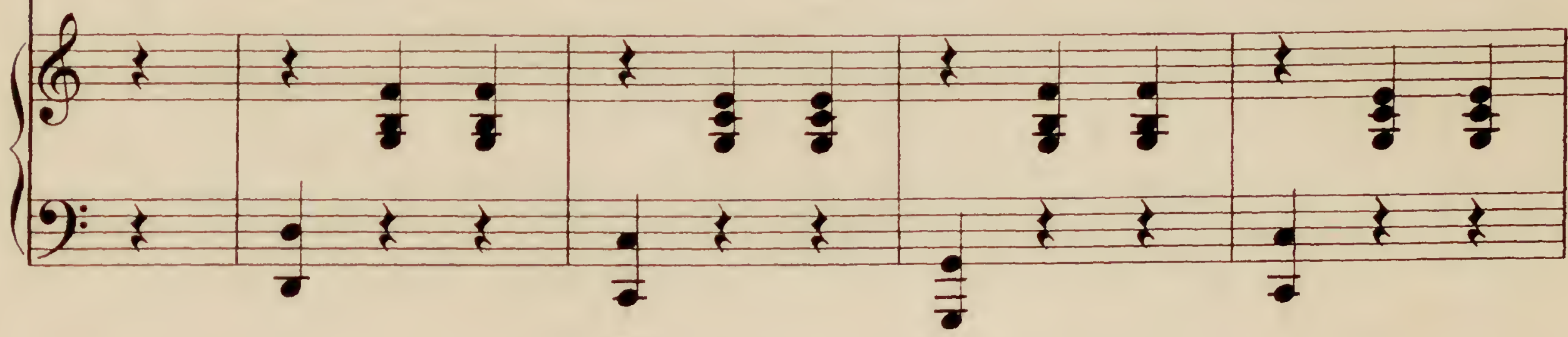

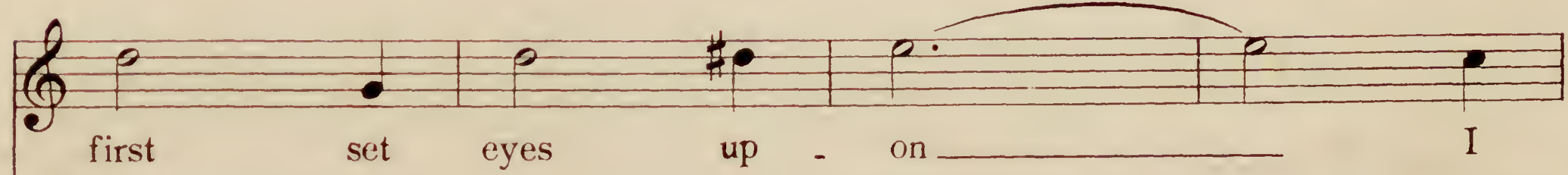

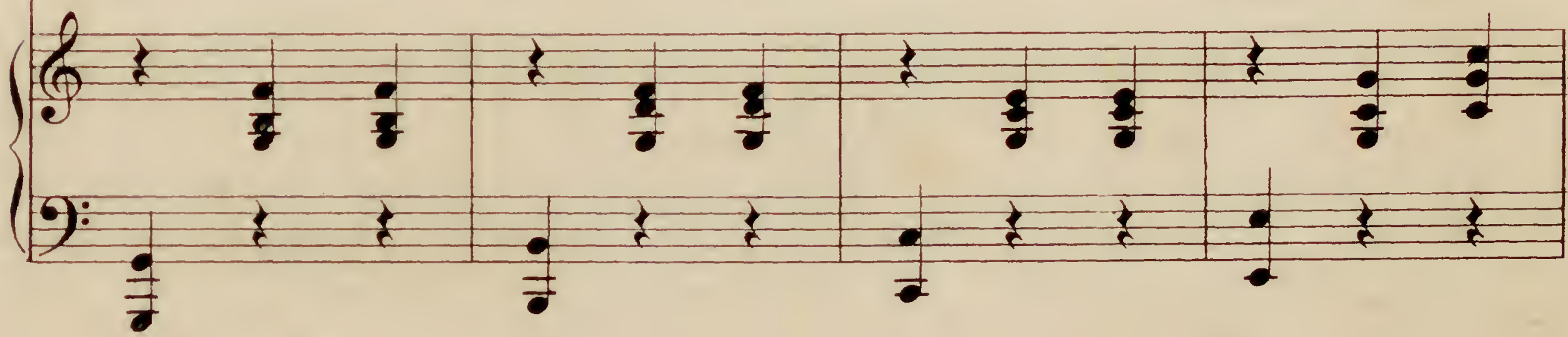

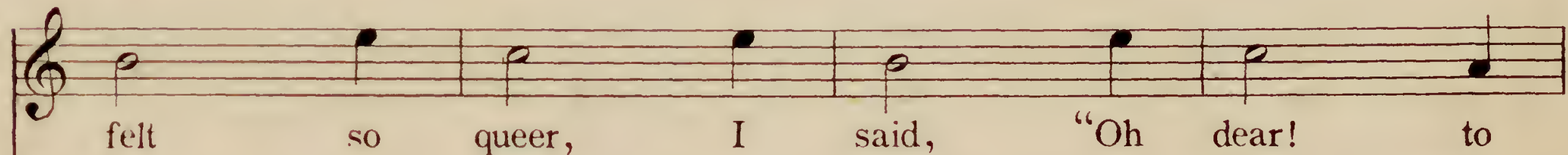

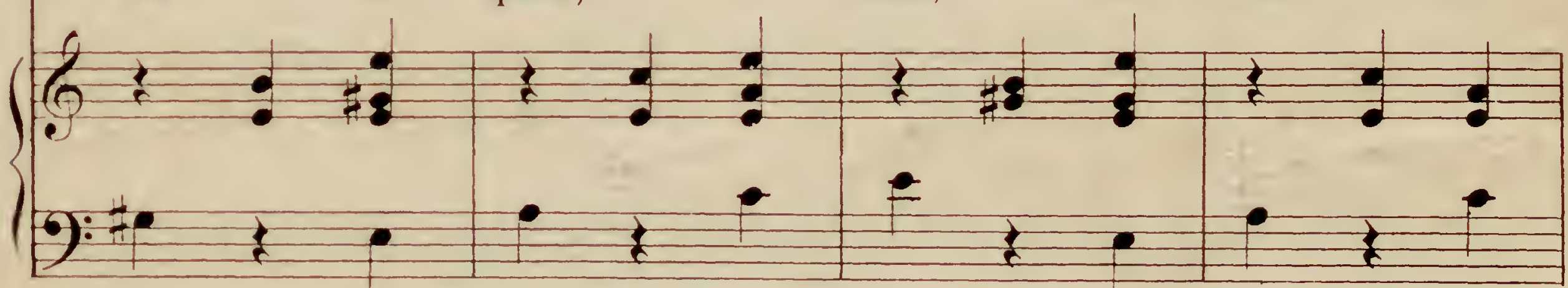
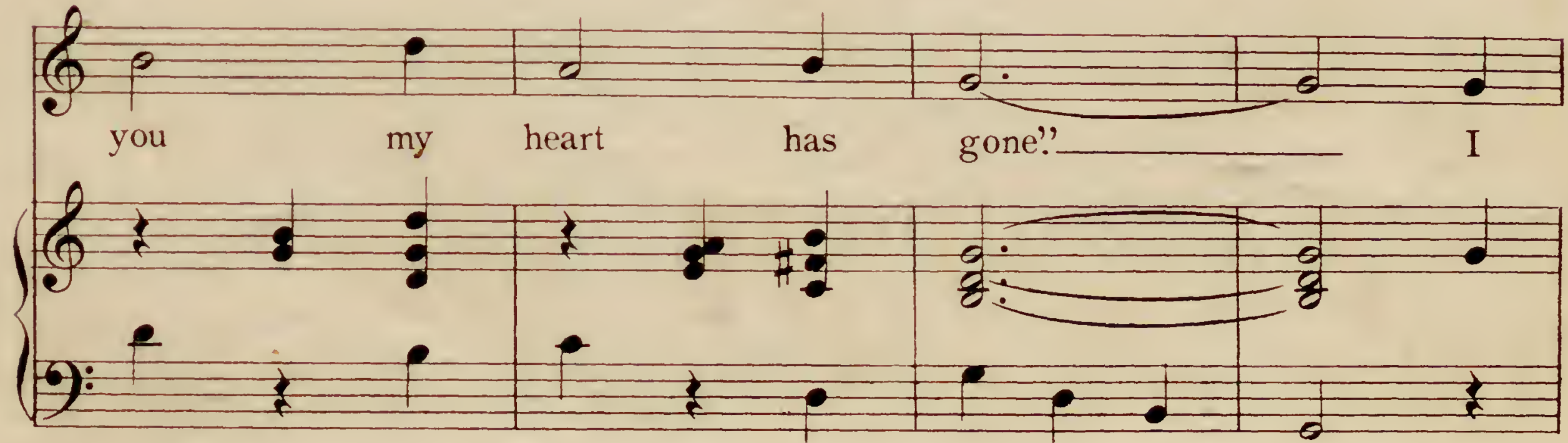

$(r)$ M.P C 1.$)$ 
\begin{tabular}{|l|l|l|l|l|}
\hline & 0 & 0 & 0 & 0
\end{tabular} brought her o'er to Eng - lands shore, and.

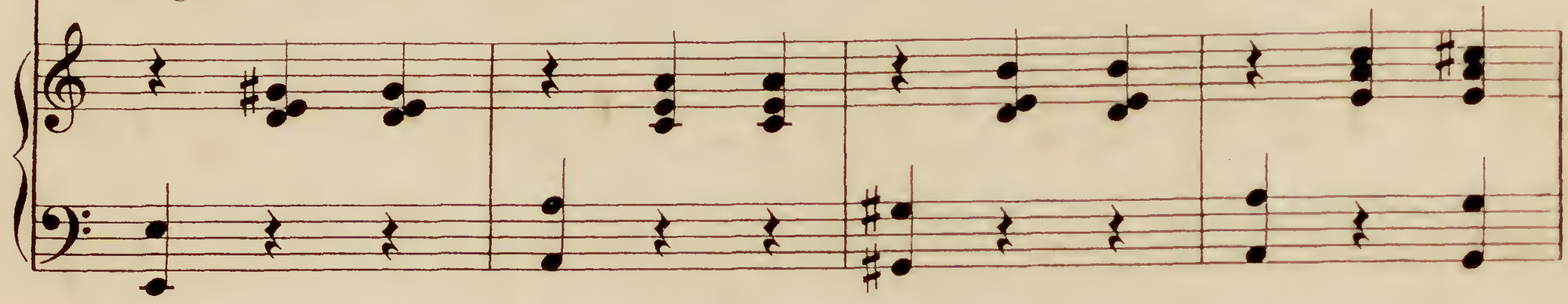



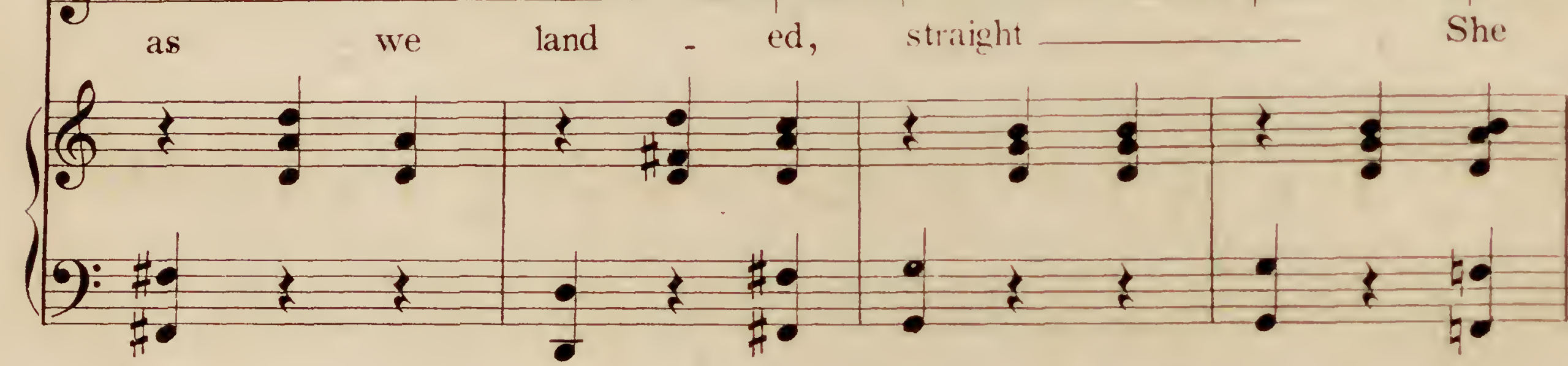
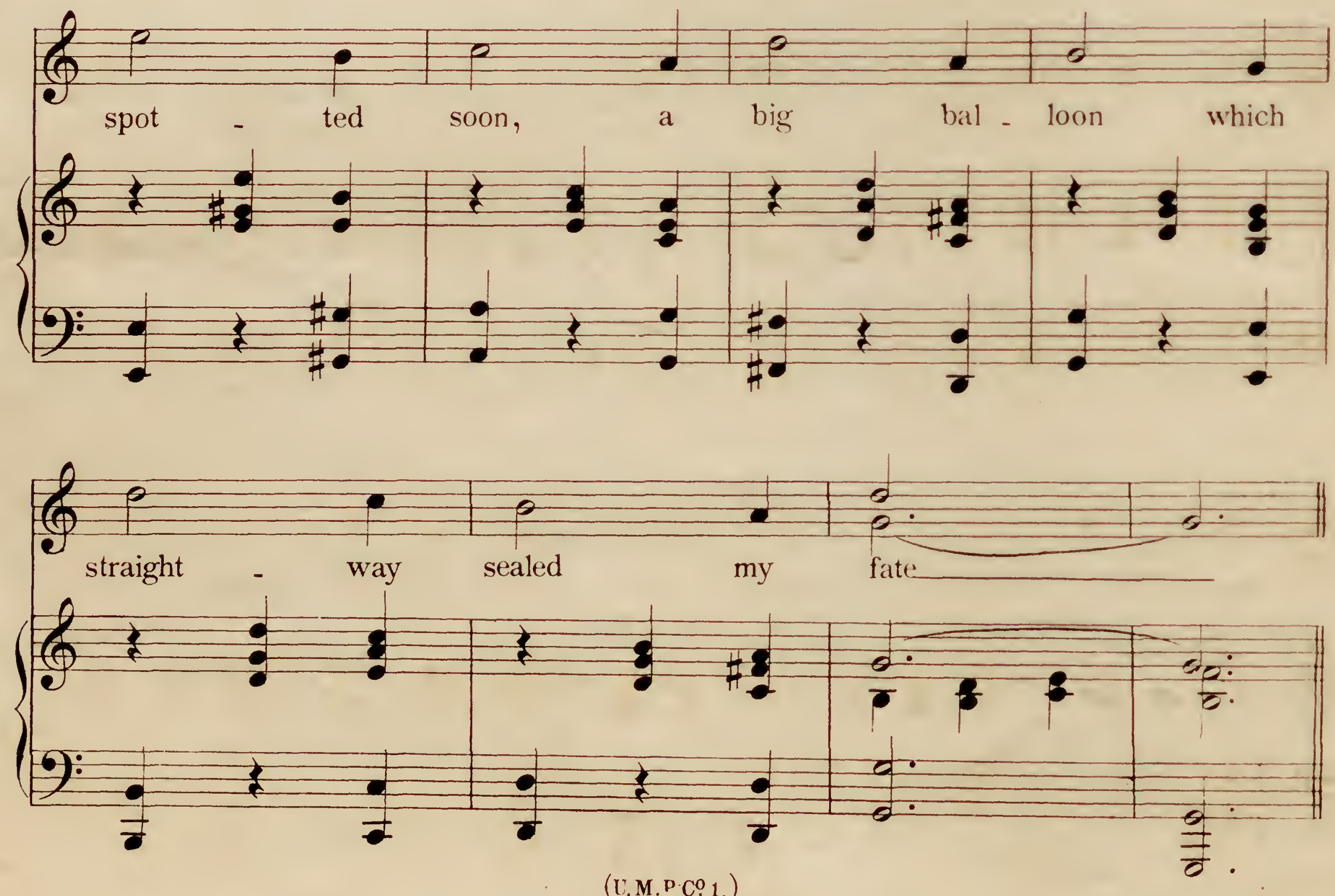
Tempo di Valse.

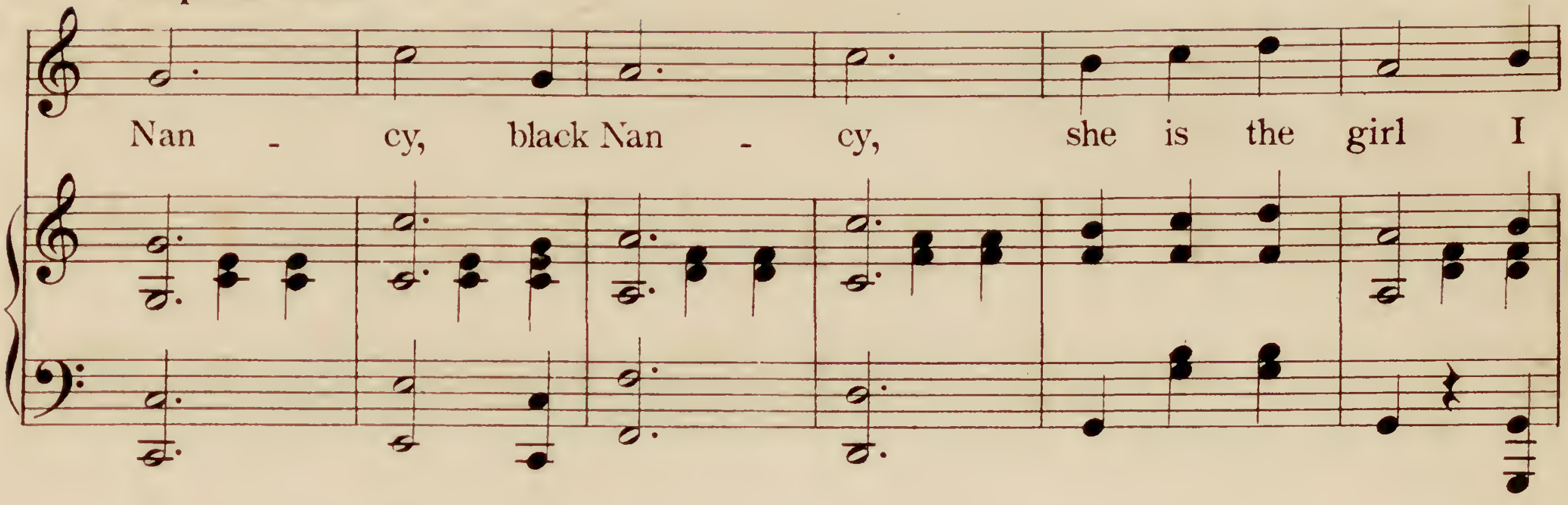

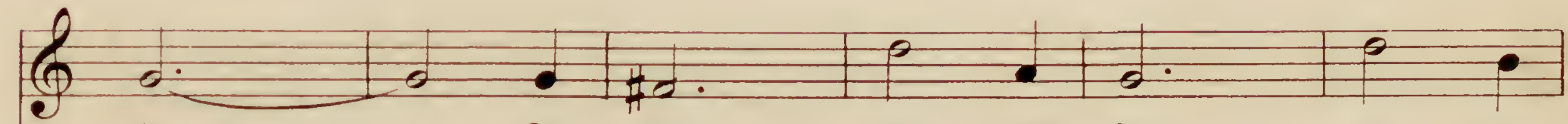
love,_ Oh Nan _ cy, my fan - cy, my

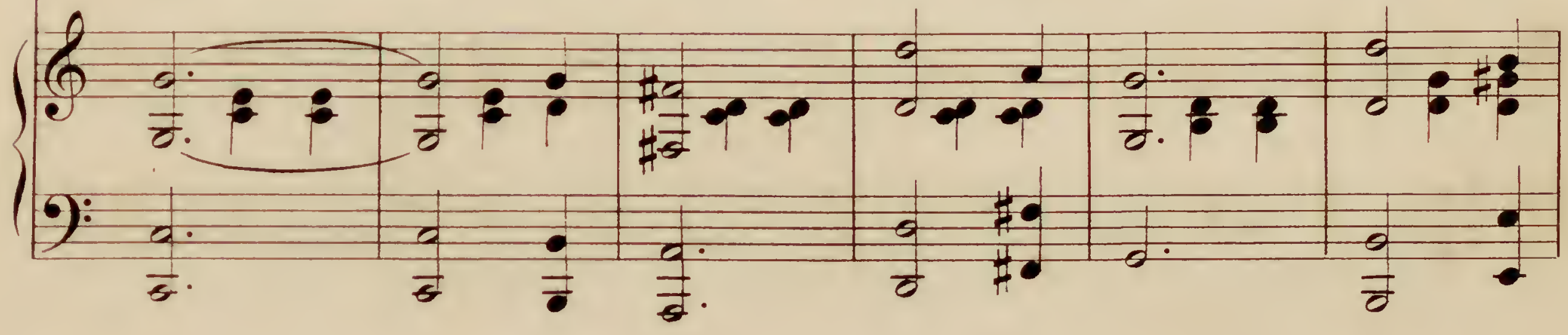

\begin{tabular}{|l|l|l|l|l|l|l|l|l|l|l}
\hline & 0 & 0 & 0 & 0 & 0 & 0 & 0 \\
\hline
\end{tabular} Af - ri - can tur - tle dove_fon From $Z u$ lu -

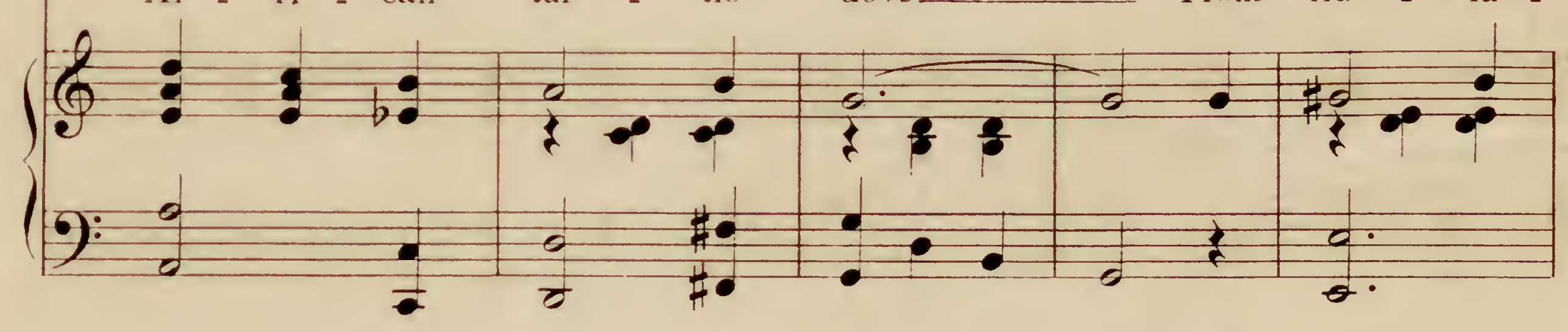

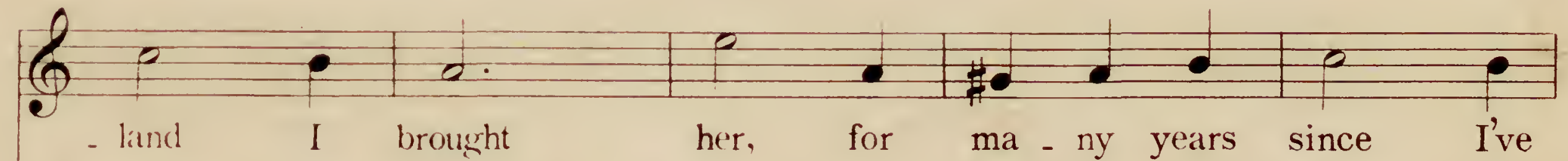

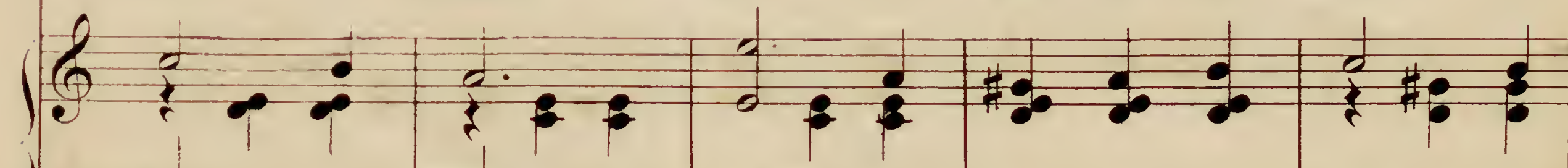

$(0): \frac{10}{10}$

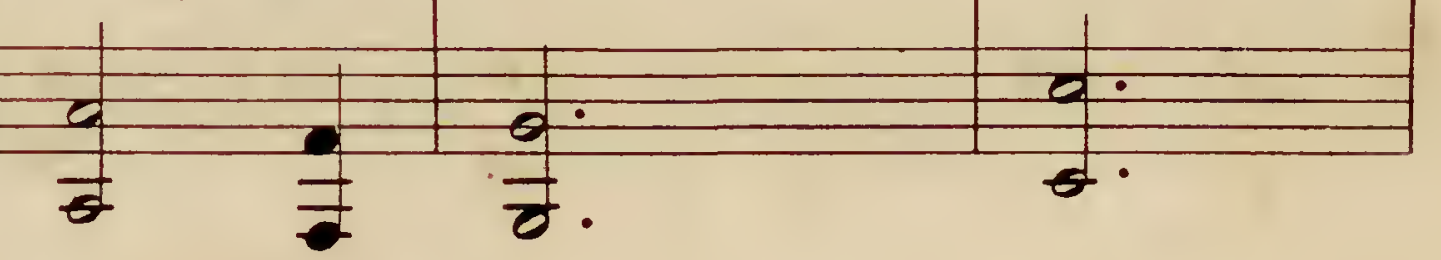

(U.M.P ( $\%$ 1.) 

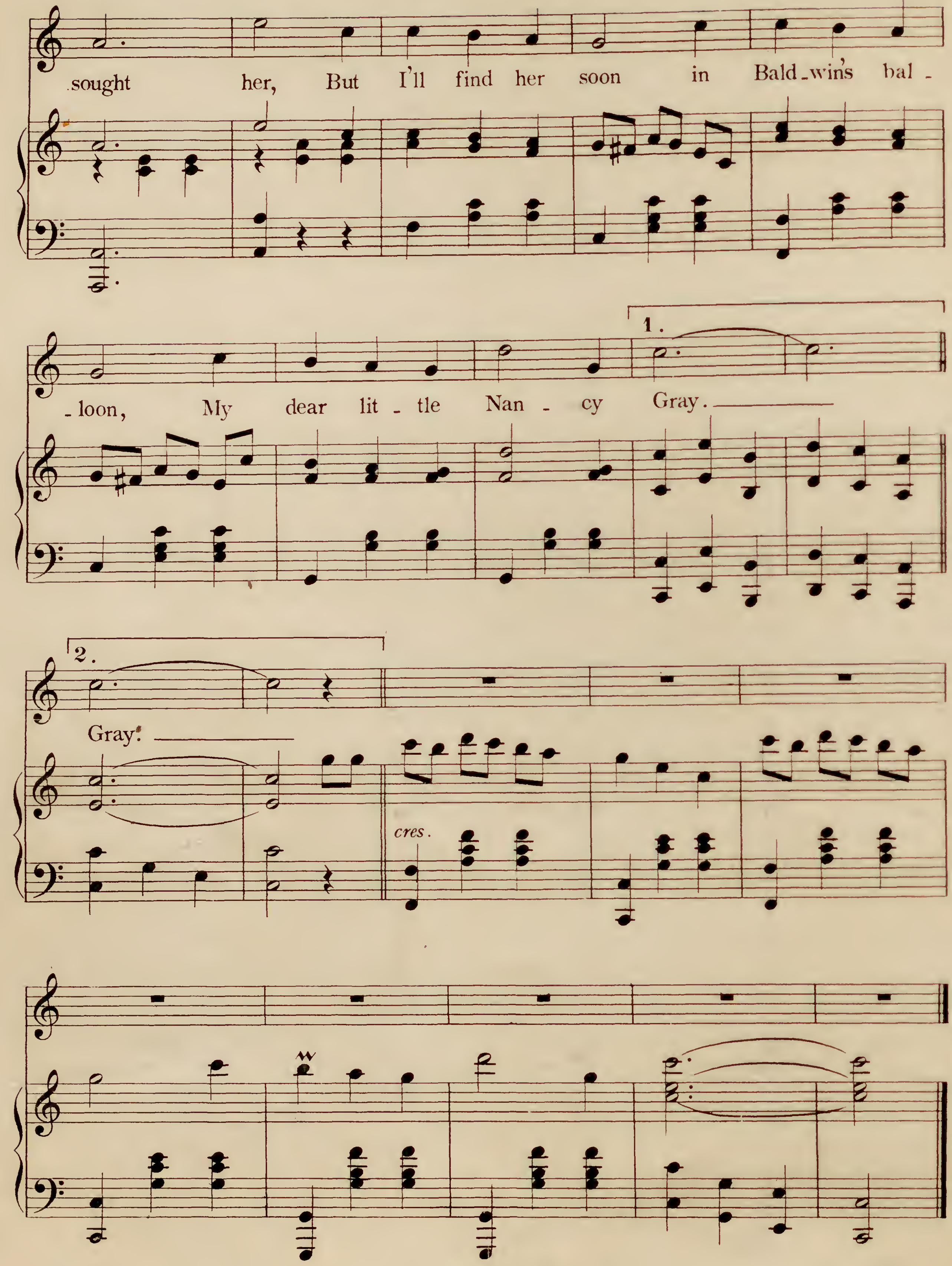

(U.M.P (OO 1) 


\section{NANCY" GRAY.}

To be sung in boys rostume holding a balloon ready for ascent.

1.

My Nancy Gray in Africa(y) I first set eyes upon,

I felt so queer, I said "oh, dear! to you my heart has gone."

I brought her o'er to England's shore, and as we landed, straight!

She spotted soon a big balloon which straightway sealed my fate.

CHORUS.

Nancy, black Nancy, she is the girl I love,

Oh Nancy, my fancy, my African turtle dove,

From Zululand I brought her,

For many years since I've sought her,

But I'll find her soon in Baldwin's balloon,

My dear little Nancy Gray.

2 .

For as the man came down, she ran and kissed him once or twice,

She said she'd love to soar above', and in about a trice

He popped her in and gave a spin, they both shot out of sight;

And now I wait and watch for fate to bring my hearts delight.

CHORUS, as before.

3.

With grief and woe, I thought I'd go up to the "milky way,"

So I've set up a parachute to follow Nancy Gray.

I'm starting now and here I vow from star to star I'll tack,

And never more land on this shore till I bring Nancy back.

CHORUS. as before.

\section{ENCHORE VERSE.}

I feel so glad, I shall go mad, or fall into a trance, Oh,joy! at last my grief is past, I've caught my Zulu Nance;

The b'loon I stopped and straightway dropped the bad man in a field, So th'honeymoon in a balloon with Nancy's signed and sealed.

\section{CHORUS.}

Nancy, my Nancy, she is the girl I love,

Oh Nancy, my fancy, my African turtle dove,

From Zululand I brought her,

And now once more I've caught her,

And the honeymoon I'll spend very soon,

With dear little Nancy Gray. 


\section{LATEST SUCCESSFUL PUBLICATIONS.}

\section{"THE QUEEN OF SONG," (VOCAL WALTZ)}

Dedicated by special permission to, and with portrait on the Title page, of MADAME ADELINA PATTI, ("THE UNDISPUTED QUEEN OF SONG,")

One of the prettiest and most melodious Waltzes ever heard, bound to find its way into every Ballroom, and into the hands of every Musician. Played at all the Popular Holiday Resorts in the United Kingdom. The Opening Melody, one of the most ear haunting Melodies ever heard, is set to pretty and graceful words.

\section{COMPOSED BY}

GEORGE BURTON, L.C.M.,

Who is undoubtedly one of the most Popular and Successful Composers of the present day.

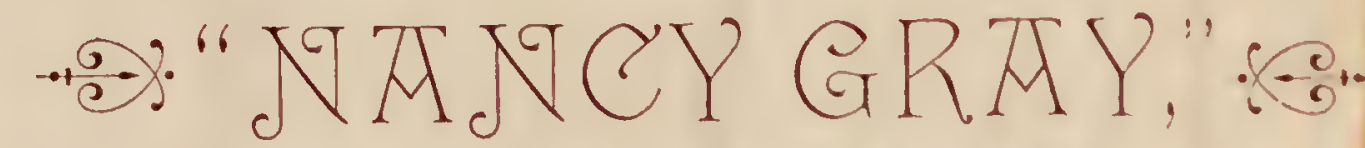

(Or, BALDWIN'S BALLOON)

The most successful Sorg of the day, a Ballad which eclipses alt that has gone before, and will rival in popularity: "Daisy Bell,"

"Dorothy Dean," \&c. The words are very original, bright and catcliy.

IVRITTEN BY

OS IV A L D LING.

The Music is one of those immensely popular waltz-time Melodies

COMPOSED BY

GEORGE BURTON, L.C.M..

A ballad which is certain to live and hecome Popular the whole world over.

SUNG BY EVERYBODY.
"THE RECORDING ANGEL KNOWS"" SEMI=SACRED SONG,

Written and Composed expressely in aid of the funds of the Sheffield Hospital \& Dispensary.

DEDICATED TO ALL SILENT SUFFERERS.

WORDS BY

O S W A L D L I N G.

MUSIC BY

GEORGE BURTON, L.C.M.

This Song will commend itself to all lovers of perfect Lyric Poetry wedded to High-class Music, and the object for which it is sold should command for it a large and ready sale.

\section{"A PAREWELE," OR, THY VASSAL, WRITTEN HY \\ A. E. BER N A.Y. COMPOSED IYY \\ PARA FELIX.}

A capital High-class Song, suitable for Drawing Foom and Ballad Concerts. Undoubtedly a valuable addition to any repertoire.

All the above Post Free, TWO SHILLINGS EACH, FROM

The Cnivensal JMusic Publishing Company, $x$ 20, BLAKE STREET, SHEFFIELD. 